\title{
The generic placement and identity of Ichneumon punctum Shaw (Hymenoptera, Mymaridae), and designation of a neotype
}

\author{
John T. Huber \\ Natural Resources Canada, Canadian Forest Service, K.W. Neatby Building, Ottawa, Ontario, Canada, K1A 0C6 \\ Corresponding author: John T. Huber (john.huber@agr.gc.ca)
}

Academic editor: Stefan Schmidt| Received 20 May 2010 | Accepted 29 September 2010 | Published 8 February 2011

Citation: Huber JT (2011) The generic placement and identity of Ichneumon punctum Shaw (Hymenoptera, Mymaridae), and designation of a neotype. Journal of Hymenoptera Research 20: 47-63. doi: 10.3897/jhr.29.865

\begin{abstract}
Ichneumon punctum Shaw, 1798, currently the type species of Anaphes, is shown to be a species of Camptoptera and is transferred to that genus as Camptoptera punctum Shaw, comb. n. A neotype from England, the type locality, is designated and described in order to define the species objectively and thus settle over two centuries of doubt about the species identity. Camptoptera punctum is compared to C. foersteri Girault, newly reported from the UK, and C. saintpierrei, the only other species so far reported from the UK. All three species are illustrated. Camptoptera aula, Debauche, syn. n., is synonymized under C. foersteri, whose host is likely Cis sp., possibly boleti Scopoli (Coleoptera: Ciidae).
\end{abstract}

\section{Keywords}

Camptoptera, punctum, history, correct generic placement, new synonym, Anaphes

\section{Introduction}

The genus Anaphes Haliday, 1833 (Insecta, Hymenoptera) currently includes about 230 nominal species of Mymaridae, several of which are used for biological control of other insects (Huber 1992, 2004). As a result, numerous publications on the genus exist. Haliday (1833: 269) first defined Anaphes in a key but without included species. In the second part of his paper (p. 346) he established the generic name Anaphes and 
described one species: A. fuscipennis Haliday. He then stated in the next paragraph "The species of this genus are numerous; mostly black, with pitchy or rust-coloured legs, and obscure or hyaline wings: Ichneumon punctum, Shaw (Linn. Trans. IV. Pl. 18, fig. 1) should be referred to it. In this species the wings are fringed with longer hairs than ordinary."

Westwood (1840: 78) listed punctum as a 'typical' (explained on p. 77, footnote) species of Anaphes. Undoubtedly, Westwood was influenced by Haliday's referral of punctum to Anaphes, and he chose punctum instead of fuscipennis as 'typical' probably because it was described earlier than fuscipennis, not because it represented an ordinary looking species of the genus. It is, in fact, not typical, as indicated by Haliday's comment about wing fringe length. Westwood's choice was accepted by most subsequent workers as a type species designation.

The problem is that it has not been possible to recognize the species I. punctum, as already noted by Graham (1982: 202). If punctum were indeed an Anaphes it would have to belong to the fuscipennis group of Anaphes s.s., as defined by Huber (1992) because of its one-segmented clava. The original material of punctum was apparently not seen by either Haliday or Westwood (Graham 1982: 205) so its placement in Anaphes must have been based on the short, inadequate original description and, in particular, Shaw's illustration. Haliday's comment about wing fringe length must have resulted from examination of Shaw's drawing. No subsequent worker has seen Shaw's specimen either, except possibly Haworth (presumably Adrian Hardy Haworth, 1767-1833), a contemporary of Shaw (Graham 1982).

Ashmead (1904: 363) selected A. fuscipennis Haliday as the type of Anaphes. If he was aware of Westwood's choice of punctum as 'typical' of Anaphes he ignored it, justifiably so in my opinion because neither Westwood nor Haliday provided any reason for assigning punctum to Anaphes. Gahan and Fagan (1923: 12) noted both type species designations for Anaphes but did not select one in preference to the other. A slide mounted specimen by Enock labeled as Anaphes punctum is in the USNM. This must be the specimen mentioned by Soyka (1949: 311), apparently based on an unpublished statement by Girault. I examined the specimen and it is clearly an Anaphes in the crassicornis group but I consider it a misidentification of punctum because it does not resemble Shaw's illustration. Incidentally, Soyka (1949: 301) discussed Curtis' (1832) apparent choice of punctum as type of the genus Mymar. Soyka did not realize that Curtis (1829: 112) placed all British mymarid names under Mymar so Soyka's discussion of Mymar versus Anaphes as the correct generic name is irrelevant; his argument was also criticized by Debauche (1949: 5). Debauche (1948: 155) treated A. fuscipennis as type species (genotype) of Anaphes, with a footnote explaining why he chose this species, and then (Debauche 1949: 6) argued forcefully for a change of genotype. Nevertheless, the choice of type species of Anaphes (or Mymar sensu Soyka) seemed to have been resolved when punctum was formally placed on the Official List of Species as the type species of Anaphes (ICZN 1965). Hellén (1974: 23) continued to treat $A$. fuscipennis as genotype, however, and Huber (1992: 26) supported previous workers to have the type species of Anaphes changed to A. fuscipennis. 
Although the question of type species of Anaphes appeared to have been formally settled, the identity of punctum continued to remain a mystery. Graham (1982) attempted to re-describe punctum from Shaw's illustration and argued for its placement in Anaphes because he thought that Shaw's illustration of punctum indicated clearly that one and perhaps as many as three of the legs had 4-segmented tarsi. He overlooked Kryger's (1950: 41) suggestion that the right hind leg of Shaw's illustration seemed to have a 5-jointed tarsi and the number of tarsal segments on the other legs were not distinctly drawn. Kryger also noted that the wings of Shaw's illustration resembled those of four genera: Anaphes, Alaptus, Camptoptera and Litus, but thought that punctum may very well have been an Anaphes. Graham suggested that there seemed to be no other genus except Anaphes that would fit Shaw's description but that it was not possible to match the figure with any species from Britain, the presumed type locality. Graham thus agreed with Kryger on the likely generic placement of punctum. He incidentally noted (Graham 1982: 206) that the Westwood collection contained a female specimen from Haworth labeled as punctum and stated that it was a species of Camptoptera "which is interesting because the wings in that genus are very like those of Shaw's figure". Graham concluded, however, that the other features of Camptoptera, such as 5-segmented tarsi and different number of antennal segments, ruled out that genus. Unfortunately, the Haworth specimen cannot be found in the Hope Museum, Oxford, or Graham's personal collection now in the Natural History Museum, London (D. Mann, J. Noyes, and C. Thurócy, in lit).

Graham (1982) stated that it was unsatisfactory to have as type-species of the genus a species that cannot be identified. I and other taxonomists would agree with this, especially when that type species is of an economically important and speciose genus such as Anaphes. Graham intended to request the International Commission on Zoological Nomenclature (ICZN) to reject Westwood's designation of Ichneumon punctum as type species and, instead, to uphold Ashmead's designation of Anaphes fuscipennis Haliday. He never submitted the request, however. The need for action is even more important because I present here strong evidence that Ichneumon punctum is not a species of Anaphes. After arguing why this is the case I designate a neotype to define objectively the nominal taxon, I. punctum. The qualifying conditions for neotype designation listed in Article 75 of the Code are addressed. A request to the ICZN to have the type species of Anaphes changed in order to promote nomenclatural stability will be submitted.

\section{Materials and methods}

Specimens of Camptoptera were borrowed from the Natural History Museum, London (BMNH) and National Museum of Natural History, Washington, DC (USNM).

Photographs of selected specimens were taken with a ProgRes C14 plus digital camera attached to a Nikon Eclipse E800 compound microscope or Nikon SNZ1500 stereomicroscope and the resulting layers combined digitally using Auto-Montage ${ }^{\bullet}$. 
Except for the neotype image, the photographs were retouched as needed with Adobe Photoshop CS4 $4^{\circ}$.

\section{Generic placement of Ichneumon punctum Shaw}

Three sources of evidence may be used to determine the best generic placement for punctum. The first is indirect, i.e., information deduced from the author and year of publication of the species, and evidence from subsequent publications, and the next two direct: 1) the preamble to the original description and the original description itself, and 2) the accompanying illustration.

Indirect evidence. The collection locality was not stated but Shaw was English and presumably collected mainly or entirely in England. The type locality is therefore almost certainly England, as Graham (1982) presumed. Shaw's species must therefore belong to one of the of the 16 genera of Mymaridae recorded from the UK (Noyes 2009), all of which occur in England. Most of the evidence about the generic placement of punctum relates to Anaphes so the features of punctum are compared or contrasted below mainly with Anaphes. Graham's (1982) discovery of the Haworth specimen labelled as punctum that Graham placed in Camptoptera is good evidence that punctum could not have been an Anaphes.

Although Shaw claimed that his drawing was accurate, both the type of microscope he used and the printing/reproduction method of the period affected detail and hence the accuracy of the published drawing, The microscope type and magnification can be inferred from year of publication. Shaw's (1798) preamble simply stated the magnification as "highly magnified". However, the useful magnification was probably only about $25 \times$ maximum (Rooseboom 1956) so the drawing is not as accurate as would be expected based on today's intrument standards. The published reproduction of Shaw's illustration also affects what is actually visible for subsequent workers to observe.

Direct evidence. The text. Shaw's (1798) preamble states, in part "This accurate microscopic drawing ..." and "... [the insect] when living, was scarce to be perceived, except when in motion on the surface of the window on which it was discovered". The 'location', on a window, is where many mymarids of different genera were often collected by later workers such as Enock, Girault, and Soyka. Generally, smaller individuals of Mymaridae are more often collected on windows than bigger ones although Soyka also collected bigger specimens because he deliberately brought hay into a shed behind his house and collected the small wasps from a window as they emerged from the hay and were attracted to daylight (Triapitsyn 2010).

Shaw's nine-word Latin description, repeated in Graham (1982: 205), is quoted again here: "Ichneumon niger, alis iricoloribus, margine pilis longissimis nigris.". It is of no help in identifying the genus, let alone the species because many species in several genera of Mymaridae could fit this description. The important points are: body colour and marginal fringe length. The iridescent colour of the wings is an artifact, possibly due to the lens quality (resulting in chromatic aberration) of the microscope used and 
may be observed in various Mymaridae under certain lights. Shaw stated that his species "was scarce to be perceived". A minute size could apply to members of several families of Hymenoptera but the illustration (antennae in particular) clearly indicates that punctum belongs to Mymaridae, even though the hind wings are not shown as stalked. The smallest English species of Mymaridae belong to Alaptus, Anagrus, Camptoptera, Cleruchus, Dicopus, and Litus. Most British Anaphes species are distinctly longer than species in these six genera. Shaw's preamble gives the colour of punctum as " . . a uniform polished black" and his description "niger nitidus" (shining black). This is indeed the colour of almost all Anaphes but also of at least one species of Camptoptera and Litus.

The illustration. One must turn to the drawing (Fig. 1, scanned from a colour photocopy of the published illustration), as previous authors did, for the best evidence about the identity of punctum.

a) Number of tarsal and antennal segments. Kryger (1950: 41) determined that the left metatarsus of Shaw's illustration had five segments. I cannot be certain of that from my own study of Shaw's drawing. My interpretation partly agrees with Kryger, except that I think the two visible tarsi on the right side as seen under a hand lens at $10 \times$ may have only four segments, as Graham suggested. This disagreement over tarsal segment number results not only from the small size of Shaw's illustration and impossibility of accurately counting how many segments were really illustrated but also the manner of reproducing illustrations at the time. The method was copperplate, which was used pre-1820, and likely the reproduction is a hand coloured line engraving because stippling is absent and there is very little bleeding of lines (Sherwood, in lit). Lithography had been invented only a couple of years previously, which was too late for Shaw's drawing to be reproduced that way. The reproduction method is simply not accurate enough to show clearly and accurately the detail needed to make an unambiguous statement about appendage number. The magnification of microscopes used at the time was also insufficient to count accurately, and therefore to illustrate correctly, the number of tarsal segments in very small insects. Prior to 1800 , microscopes could only provide up to about $25 \times$ magnification beyond which image curvature, astigmatism, and spherical and chromatic aberration were chiefly to blame for poor quality images (Rooseboom 1956: 14). An achromatic system for microscopes was only produced about 1791, probably too late for Shaw, who illustrated his punctum sometime in the mid-1790s ("some years ago", as stated in his 1798 paper).

It is noteworthy that another habitus illustration, that of Mymar pulchellum (Curtis 1832: folio 411), shows one leg clearly with the tarsus 5-segmented and the other legs either with four segments each or not accurately countable. The detail of one leg (fig. 8) also seems to show five segments. Mymar is a genus whose species all have 4-segmented tarsi so evidently the number of tarsal segments in published drawings of that period are unreliable and one should not use them to determine tarsal segment number and, consequently, tarsal number to determine the genus or even the general group of genera to which a species might belong. The same argument applies to the number of antennal segments. In the $M$. pulchellum illustration the number is impos- 


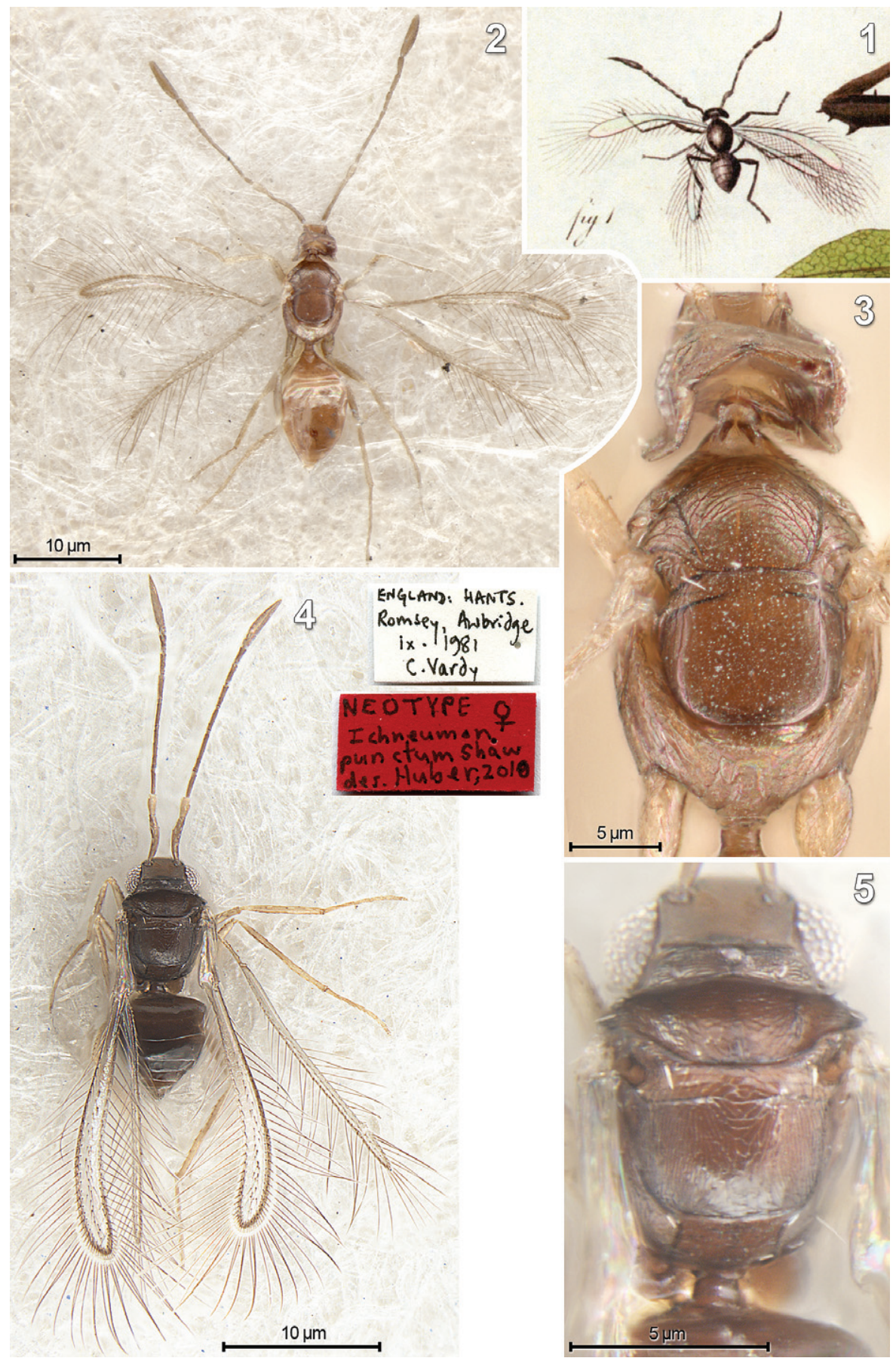

Figures I-5. I Ichneumon punctum Shaw, scanned reproduction of Shaw's original figure $\mathbf{2}$ Camptoptera foersteri Girault, habitus dorsal (air dried specimen from High Beech, Epping [Forest], East Sussex, England) 3 C. foersteri, mesosoma dorsal 4 I. punctum, neotype, habitus dorsal (critical point dried specimen) 5 I. punctum, neotype, mesosoma dorsal. 
sible to determine. In Shaw's illustration there appear to be only five segments between the scape and clava. In the British (and European) fauna that number occurs only in species of Alaptus and Arescon. All Anaphes females have six funicle segments (though segment 1 is short) and Camptoptera have seven, but segment 2 is so short (ring like) there are effectively only six visible segments. Segment 1 may be fairly short, depending on species. Consequently, both tarsal and antennal segment numbers as purportedly determined from Shaw's illustration may be discounted as being sufficiently accurate to determine the generic placement of punctum. Other elements of Shaw's illustration must be given greater weight in determining its generic placement.

b) Wings. The maximum wing width and maximum fringe seta length should not vary independently, so the proportions will remain the same regardless of the magnification used to view the specimen or the type of plate reproduction (copperplate, hand painting, lithography, line drawing) or the final size of reproduction on the published plate. Assuming Shaw's drawing really was accurate the wing proportions must therefore be correct. Measuring the wing parts of Shaw's drawing at about 20x give a wing width to fringe seta length of about 1:3.

Bouček and Graham (1978) listed nine species of Anaphes (Anaphes) and five in A. (Patasson) in Britain. The specific epithet punctum was listed under A. (Anaphes) with a symbol beside it indicating that the name is presumed or known to be invalid. Besides punctum, only three species from the British list remain in the fuscipennis species group: aries, auripes, and regulus; Graham (1982) placed in synonymy or transferred the other five to A. (Patasson) [= crassicornis group of Anaphes (Huber 1992, 2004), defined by having a 2-segmented clava in females]. If Shaw's specimen was indeed collected in Britain, the only possible Anaphes candidates for punctum are the three listed above. All three have much wider wings relative to marginal fringe length so on this basis cannot be punctum. In Europe, the only species of Anaphes with such narrow wings and long marginal setae is $A$. angustipennis Debauche, which also belongs to the crassicornis group but has not been recorded from the UK. In addition, the wing shape is wrong and its surface is fairly uniformly covered in microtrichia. One Oriental Anaphes sp. has a suitably narrow forewing (Huber 1992: fig. 7) but neither it nor $A$. angustipennis can be considered species that Shaw would have collected and illustrated. The wings of various Anaphes (Huber 1992, 2004) and species in the Camptoptera group of genera (Huber and Lin 1999, figs 112 and 113) show that Shaw's drawing is closer to Camptoptera than to Anaphes.

It is curious that Graham (1982) worded the wing proportions the way he did when he provided descriptive notes on A. punctum based on Shaw's illustration. $\mathrm{He}$ compared the relative length of the longest marginal setae to the length (his italics) of the fore wing, instead of the usual method of comparing their length to the maximum width of the wing. It is almost as though he did not want to draw attention to the incontrovertible fact that the wing setae on Shaw's drawing are unusually long for an Anaphes, as Haliday (1833) had long since noted.

The curvature of both fore wings and the left hind wing of I. punctum is pronounced, indeed too much so for the hind wing, so Shaw's drawing is somewhat fan- 
ciful in this regard. No described European genus of Mymaridae has such an evenly curved fore wing from the base to the apex. One explanation for the exaggerated wing curvature might be spherical aberration, which had not been overcome in objective lenses before about 1800 (Rooseboom 1956). Another reason for the extreme curvature is that the posterobasal widening of the fore wing is not shown in Shaw's drawing but does occur in Camptoptera and other mymarid genera. Most Camptoptera species have the fore wing distinctly curved distally as a result of the posterior margin of the wing being concave (Figs 2, 4, 6, 13). Members of this genus are the closest example of uniform fore wing curvature to Shaw's drawing. Kryger (1950) illustrated a representative of each genus of European Mymaridae. Comparison of his dorsal view habitus line drawings shows that the only genus closely resembling Shaw's illustration is a species of Camptoptera (p. 45). All Kryger's other drawings show species with straight forewings, including Anaphes (p. 40) and Patasson (p. 85), a synonym of Anaphes.

The width of the fore wing distally compared to proximally is too great for most European Camptoptera but is too little for Anaphes species. The hind wings are somewhat fanciful in that they appear distinctly wider distally than proximally, the wing membrane apparently extends to the wing base, and the apex is broadly rounded. No mymarid, from Europe or elsewhere, has such a hind wing though the fringe length could apply to any mymarid hind wing.

The lack of microtrichia on the surface of the fore wing in Shaw's illustration might indeed be due to omission by Shaw, as Graham (1982) suggested, but more likely it is because species of genera such as Camptoptera usually have only one or two rows of them, in contrast to Anaphes, whose species always several rows of microtrichia, thus giving the wing a fairly uniformly setose appearance.

c) Head. The lenticular head of I. punctum (Fig. 1) is somewhat fanciful. No mymarid has such an evenly convex anterior surface as seen in dorsal view (spherical aberration again?). Camptoptera species, however, have a sharply margined occiput that is concave, almost exactly as illustrated by Shaw, thought the head is usually thicker and the anterior margin is straighter. Anaphes species have a similar head but with the occiput not quite so sharply margined or concave.

d) Antenna. Antennal proportions, particularly the length of the clava compared to its width, are similar in I. punctum and various Camptoptera species. The antennal clava is as long as the three apical funicle segments on Shaw's figure (Fig. 1). Most Anaphes species have a relatively shorter clava, at most about as long as two apical funicle segments combined, whereas Camptoptera species usually have a longer, narrower clava often as long as the three apical funicle segments together. As Graham (1982) pointed out, the peculiar shape of the clava illustrated by Shaw is likely due to collapsing of the clava near the middle though this does not necessarily happen in air-dried specimens (Fig. 2). In specimens that are not shrivelled the clava would normally be slightly wider medially than apically. The multiporous plate sensillum (mps) on the clava shows up as a single, fairly long, white median longitudinal line on Shaw's illustration. Camptoptera species have only one such sensillum on the dorsal 
surface and it extends almost the entire length of the clava. It is noticeable (Figs 2, 4, 6) as a white streak in certain lights. The clava of Anaphes species does not have such an mps length or arrangement.

e) Metasoma. The gaster shape and attachment of the metasoma to the mesosoma in Shaw's illustration resembles that of either Camptoptera species (Figs 2, 4, 6) or species of other genera including Anaphes, but is fanciful in that no mymarid mesosoma is ever so strongly and evenly rounded. Members of both genera have a very short petiole, but that of Camptoptera is much narrower than in Anaphes. Usually the petiole simply is not visible at all, however. Shaw certainly did not, and evidently could not, illustrate it because it is so small; in fresh or critical point dried specimens it tends to be less visible (Figs 3, 5) though in air-dried specimens with the gaster collapsed it may be clearly visible (Fig. 2). The definite constriction between mesosoma and metasoma is clear, however. The gaster is widest just posterior to constriction and tapers gradually thereafter. This is more noticeable in Camptoptera species, whose gaster tends to be slightly shorter and more triangular (cone shaped) in dorsal view than in Anaphes species.

The evidence presented above conclusively excludes punctum from Anaphes. The remaining 15 British genera can be eliminated from consideration on the basis of colour, size or wing proportions, although on the basis of minute size alone Alaptus, Dicopus, and Litus could be possible candidates in which to place punctum. However, only Camptoptera has the general habitus and details of structure, especially the curved forewing, that match Shaw's drawing. Only one species in Britain has the shiny, almost black colour described by Shaw. It is evidently a rarely collected species as only 1 was found among the 62 card-mounted, unsorted specimens received for study from the $\mathrm{BMNH}$. That specimen is designated as neotype and described below, and the generic transfer from Anaphes is formalized.

\section{Taxonomy}

Camptoptera punctum (Shaw), comb. n.

Figs 1, 4, 5

Ichneumon punctum Shaw 1798: 189 (description), 192 (plate 18, fig. 1, illustration); Soyka 1949: 301 (discussion of type species).

Anaphes punctum; Haliday 1833: 341 (footnote), 346 (generic transfer); Westwood 1840: 78 (listed as 'typical' species), 169 (reference to body size); Dalla Torre 1898: 424 (catalogue); Ashmead 1904: 363 (type species of Anaphes); Schmiedeknecht 1909: 499 (list); Gahan and Fagan 1923: 12 (genotypes of Anaphes); Debauche 1948: 55 (mention); Debauche 1949: 6 (mention); Kryger 1950: 6 (repetition of Westwood's diagnosis), 40 (repetition of Shaw's description); ICZN 1965: 82 (Official List); Bouček and Graham 1978: 110 (British list); Graham 1982: 204. (All 
incorrect generic placement); Huber 1992: 26 (suggested type species change), 31 (type species of Anaphes), 76 (list). (incorrect generic placements.) Mymar punctum; Curtis 1929: 112 (list); Curtis 1932: folio 411 (type species of $M y$ mar [in the broadest sense, i.e., equal to Mymaridae]); Soyka 1949: 301 (discussion of Curtis' designation of type species), 311 (mention of slide-mounted specimen identified as punctum). Soyka 1955: 470 (redescription, "typisches Stück" designation). (All incorrect generic placements.)

Etymology. The specific epithet, punctum, is a noun in apposition whose meaning is 'dot' or 'point', undoubtedly as Shaw intended, so it retains its neuter ending. If treated as an adjective with a feminine ending (puncta) it would have a different meaning (Brown 1978), unintended by Shaw.

Neotype female (BMNH), here designated. The specimen is critical point dried, in excellent condition, mounted dorsal side up on a card and labelled (Fig. 4) 'England: Hants. Romsey, Awbridge ix.1981 C. Vardy'. A red label reading 'NEOTYPE + Ichneumon punctum Shaw des. Huber 2009' has been added to the specimen.

A neotype is designated because the species is unrecognizable and yet it is currently accepted as type species of the genus Anaphes. The neotype is designated specifically to clarify the taxonomic status of the species. In order to provide nomenclatural stability the ICZN will be petitioned to formally transfer punctum to its correct genus but this requires that the species be objectively identifiable.

The species description below emphasizes features that can be compared directly with Shaw's illustration, particularly proportions of body, wings and antennae. Shaws' drawing has approximately the following proportions: antenna $1.4 \times$ body length, clava as long as apical 3 or 4 funicle segments and 0.6 or $0.7 \times$ funicle length, depending on which one is measured, mps extending almost length of clava, fore wing marginal setae about $3 \times$ wing width. Structures on the neotype were examined and measured at up to $200 \times$ magnification, as much as eight times the magnification that Shaw could have effectively used.

Diagnosis. Besides C. punctum, only two other British species of Camptoptera are recorded: C. papaveris Förster and C. saintpierrei (Bouček and Graham 1978) A fourth species from the United Kington is newly reported here: C. foersteri Girault. Camptoptera punctum (Figs 1, 4, 5) differs from C. foersteri (Figs 2, 3, 9-13) by funicle segment 1 relatively longer, mesoscutum (entire mesosoma as well) shorter and wider, pronotum and metanotum not visible in dorsal view, notauli faint, becoming evanescent posteriorly, and petiole with a lateral lamella. Camptoptera aula Debauche, syn. n., is placed here in synonymy under $C$. foersteri. A specimen of Cis sp., probably boleti Scopoli (Coleoptera: Ciidae) [det. P. Bouchard, CNC) is card mounted with 20 males and females of $C$. foersteri (each on its own card), suggesting that this beetle is the host whose eggs are parasitized by the mymarid. Camptoptera punctum appears to differ from $C$. papaveris Förster by the relatively wider fore wing and, apparently the much more weakly concave occiput. Förster's original description of Camptoptera (the morphological features of $C$. papaveris are given only in 


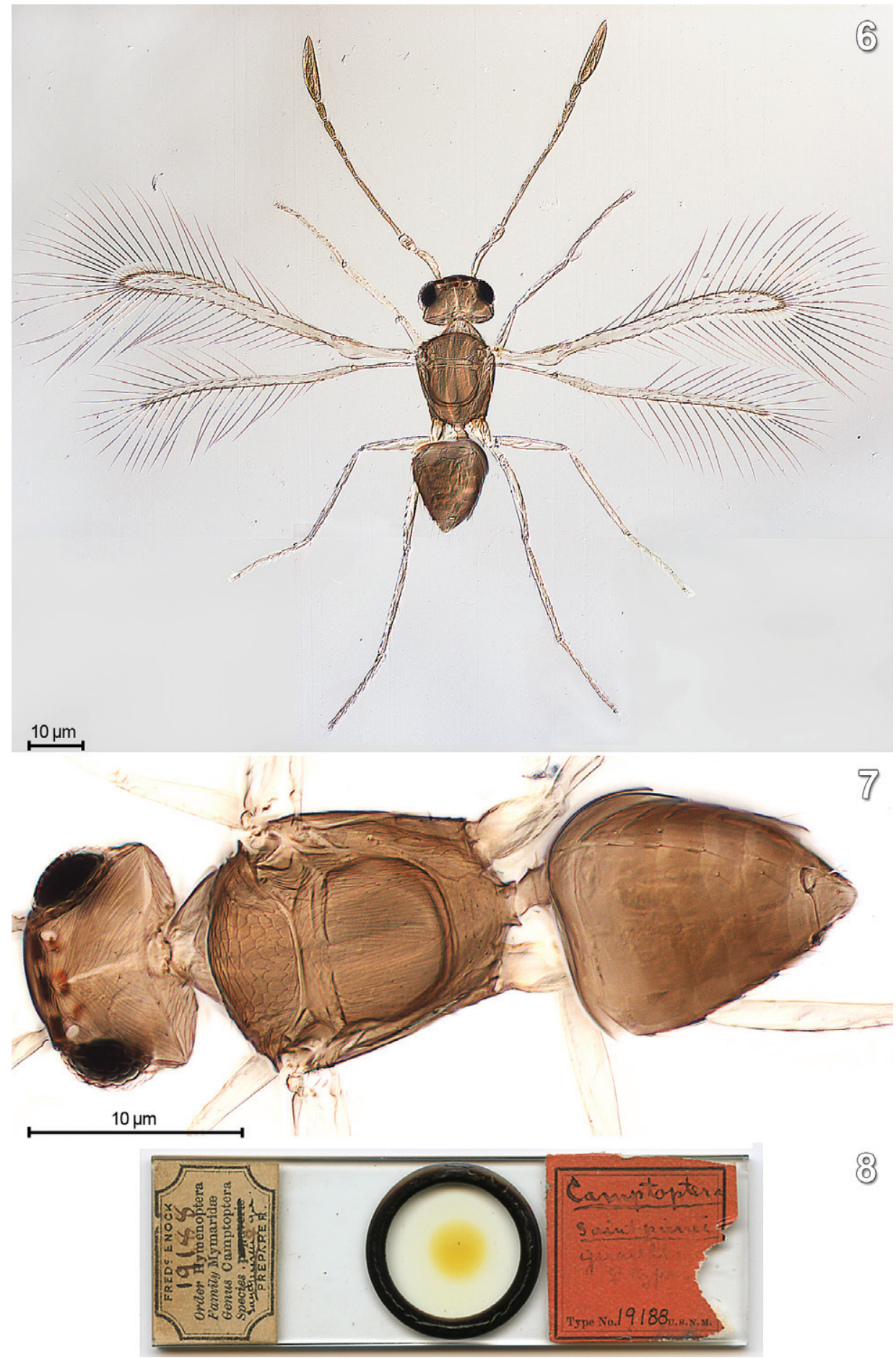

Figures 6-8. Camptoptera saintpierrei Girault, holotype. $\mathbf{6}$ habitus, dorsal $\mathbf{7}$ body, dorsal 8 holotype slide (USNM). 
the generic description) and Soyka's (1961: 82) redescription of papaveris based on a specimen from Holland, are not very satisfactory to define the species. The type is represented by a fragment only. The species identity and definite distinguishing features from C. punctum cannot be determined here. Girault (1909) redescribed what he though was $C$. papaveris from a beautiful preparation by F. Enock (Figs 6-8) but then (Girault 1915) decided it represented a new species, which he named C. saintpierrei. Camptoptera saintpierrei differs from $C$. punctum by having funicle segment 1 almost as long as segment 2 (Fig. 6), a slightly narrower and less curved fore wing (Fig. 6), and narrower mesosoma with the scutellum longitudinally striate (Fig. 7) instead of reticulate.

Description. Colour. Body very dark brown, shiny (Fig. 4). Face and gena lighter brown than vertex. Eye and ocelli silvery grey. Scape brown dorsally, yellow laterally and ventrally, pedicel yellowish with some brown laterally and ventrally, flagellum light brown. Legs light brown except coxae brown, femurotibial joints, apical half of tibiae, and tarsi yellowish. Fore wing with humeral plate light yellow, submarginal vein light brown, and marginal vein brown. Wing membrane with a narrow, distinct brown border along anterior margin, around wing apex, and along posterior margin in apical fifth (as measured from apex of venation).

Head. About $2.1 \times$ as long as wide and $1.1 \times$ as high as wide, in dorsal view with anterior margin only slightly convex, posterior margin distinctly concave, and occiput sharply margined. Eye round, only slightly longer than malar space. Ocelli elliptical, in low triangle with OOL:POL:LOL $=10: 60: 25$. Vertex with faint transverse striatereticulate sculpture, with 2 short white setae between posterior ocelli, and 2 between eye orbit and dorsal trabeculae. Face with 4 pairs of white setae: 2 between and below toruli, and 2 below level of ventral margin of eye.

Antenna. Antenna almost $1.3 \times$ body length. Scape with 5 short, blunt setae dorsally and 1 longer seta ventrally. Pedicel with 2 short blunt seta dorsally and apparently 2 ventrally. Flagellum almost $0.8 \times$ antennal length, clava $0.4 \times$ funicle length, as long as the 3 apical funicle segments together, and, in certain lights, a thin, white longitudinal multiporous plate sensillum about $0.7 \times$ claval length clearly visible (Fig. 4 , right antenna).

Mesosoma. Pronotum and metanotum in dorsal view not visible except slightly laterally (Figs 4, 5). Mesoscutum with notauli faint, becoming evanescent posteriorly; mesoscutum, scutellum and frenum with faint, raised isodiametric reticulation, on scutellum more or less isodiametric anteromedially, becoming distinctly elongate anterolaterally. Axilla with short but distinct white seta. Propodeum with widely spaced, straight, submedian carinae diverging anteriorly at metanotum, with the area between covered with minute spicules. Propodeal seta white, near posterolateral angle of propodeum.

Wings. Fore wing with about 30 microtrichia medially on membrane, about 6 in one longitudinal, median row beginning about $0.2 \times$ wing length beyond apex of venation and the remainder in two irregular rows thereafter, extending to wing apex. Longest marginal setae about $4.2 \times$ maximum wing width. 


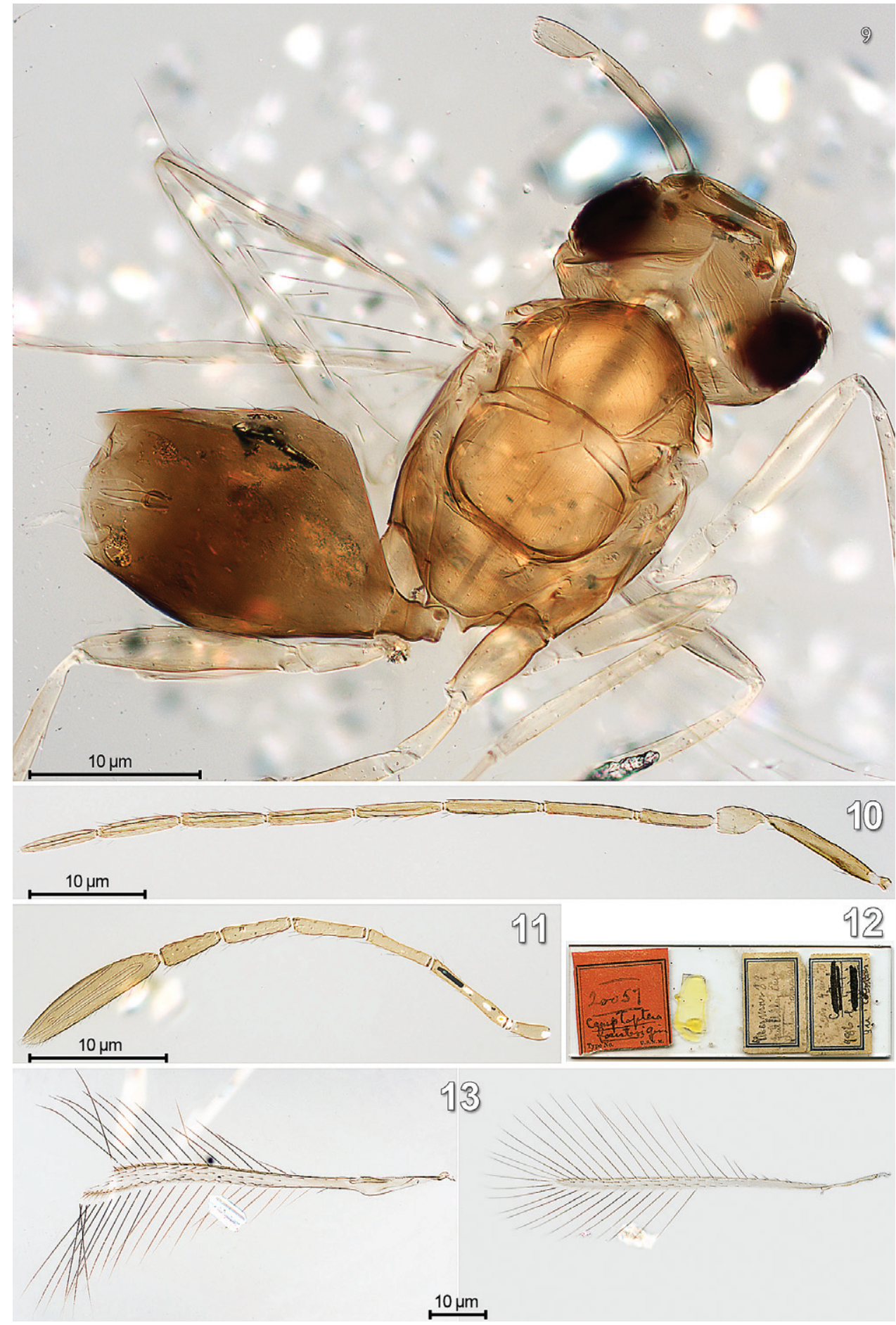

Figures 9-I3. Camptoptera foersteri, paratypes; 9 Body, female $\mathbf{I} \mathbf{0}$ antenna, male I I antennal flagellum, female $\mathbf{I} \mathbf{2}$ paratype slide (USNM) $\mathbf{I} \mathbf{3}$ wings. 
Metasoma. Petiole $0.5 \times$ as long as greatest width, with a light brown lateral flange at anterior margin about $0.3 \times$ petiole width and with an apical seta as long as the flange itself. Gaster cone shaped, smooth and shiny, with gastral tergum 1 almost vertical, tergum 2-8 horizontal or almost so, with up to 3 pairs of decumbent, lateral or sublateral white setae on dorsal surface. Cerci white, curved, not extending past apex of gaster.

Measurements (in micrometers). Body length 480. Fore wing length 700 and width 60, longest marginal cilia 250. Head width 155 and length 75, mesosoma length 190 and width 160, petiole length 20 and width 45, gaster length 210 and width 185 . Total length of antenna 580 ( 605 by adding measurements of individual segments). Antennal segments (length/width): scape 95/23, pedicel 40/20, $\mathrm{fl}_{1} 55 / 10, \mathrm{fl}_{2} 5 / 10, \mathrm{fl}_{3} 85 / 10$, $\mathrm{fl}_{4} 50 / 10, \mathrm{fl}_{5} 53 / 10, \mathrm{fl}_{6} 48 / 15, \mathrm{fl}_{7} 45 / 15$, clava $135 / 25$.

\section{Discussion}

Haliday's error in assigning Ichneumon punctum to Anaphes was accepted fairly uncritically by subsequent workers, some of whom tried to explain why Anaphes was the best genus for it. Their arguments are unconvincing. A more critical examination of Shaw's illustration should have led someone to realize that punctum cannot possibly belong in Anaphes but rather to Camptoptera. Wing curvature alone would have been a sufficient reason to exclude punctum from Anaphes. Although interpretation of a published drawing is subjective and unacceptable for determining the type species of a genus no matter how accurate the author claims his drawing to be and even if its generic placement were not in doubt I nevertheless argue above that the weight of evidence, particularly the wing shape and setation, antennal clava, and shape of head, strongly favours placement of punctum in Camptoptera. An air-dried Camptoptera foersteri from High Beach, Epping [Forest], Essex, England (BMNH) (Figs 2, 3) in dorsal view with wings outstretched shows how similar a Camptoptera species is to Shaw's drawing. Almost any species of Camptoptera from Europe or North America would have served just as well though most of the species have narrower wings than Shaw illustrated.

The Haworth specimen labelled as punctum is objective proof that Shaw's specimen of punctum must have belonged to Camptoptera. Graham may have belatedly realized that. Possibly Haworth may have been the only person who actually saw Shaw's specimen, which would have permitted him to make his species identification, though of course he would have left it in Ichneumon as no genus of Mymaridae had yet been described. Had Graham accepted that punctum belonged to Camptoptera it would have strengthened his intended submission to the ICZN to have A. fuscipennis declared type species of Anaphes. Graham was apparently unaware that Soyka (1955) had redescribed Mymar punctum from a specimen collected by him on a window in Krössbach (Austria, Tirol), which he designated as "typisches Stück", i.e, typical specimen. In the preamble to his redescription, Soyka stated that punctum is the genotype 
of this genus. He further stated that according to Shaw's drawing it seemed to him that the species was best suited as genotype of the genus and the drawing most of all resembled it. Soyka did not provide a formal neotype designation but only a 'typical specimen' designation, and offered no differential diagnosis or, indeed, any comparison with related species. Further, his specimen is not from the presumed type locality, i.e., England, and his designation cannot be considered a valid designation of a neotype. It may safely be ignored.

It is unacceptable to have a type species that belongs to the wrong genus. Removal of Ichneumon punctum from Anaphes to Camptoptera leaves only A. fuscipennis as the original species in Anaphes (Haliday 1833: 346) and therefore the only candidate for type species. Anaphes fuscipennis is widely distributed throughout Europe and eastern North America, is one of the most easily recognizable species of Anaphes in a large genus many of whose species are not easily identifiable, has been objectively defined (lectotype designated by Graham 1982), and has a considerable literature associated with it because of its use as a biological control agent of Sitona humeralis Stephens and Hypera spp. (Curculionidae) in North America (Huber 1992). For nomenclatural stability it would be simplest to accept A. fuscipennis as the type species of Anaphes, following Ashmead (1904). To do otherwise would create a major nomenclatural problem because of the large number of named Anaphes species and the considerable biological control literature on some of them, as catalogued by Noyes (2009).

Graham (1982: 206) ended his discussion of Anaphes punctum with the comment that he would request the International Commission on Zoological Nomenclature (ICZN) to reject Westwood's designation of Ichneumon punctum as type species of $A n$ aphes (ICZN 1965) and uphold Ashmead's designation of A. fuscipennis as type species of the genus. The Haworth specimen of punctum would have been the logical choice as neotype, but since it cannot be found despite a thorough search another specimen is designated here. A separate submission to the ICZN to have Anaphes fuscipennis formally placed on the Official List of type species is being prepared.

\section{Acknowledgements}

I thank P. Madaire, librarian, CNC, Ottawa and B. Sherwood, Assistant Librarian, Linnaean Society of London, for information on the type of illustration in Shaw (1798). J. Hogan (Hope Museum, Oxford), J. Noyes (Natural History Museum, London) and C. Thuróczy (Köszeg, Hungary), are gratefully acknowledged for searching for the Haworth specimen of punctum in the Hope Museum of Oxford University, Oxford, and the Natural History Museum, London, respectively. M. Gates (USNM) is gratefully acknolwedged for the loan of the holotype of $C$. saintpierrei and paratype of $C$. foesteri. I thank especially my technician J. Read for taking the photographs and compiling them into a plate for optimal comparison and proofreading the manuscript. 


\section{References}

Ashmead WH (1904) Classification of the chalcid flies of the superfamily Chalcidoidea, with descriptions of new species in the Carnegie Museum, collected in South America by Herbert H.H. Smith. Memoirs of the Carnegie Museum 1(4): 225-555.

Bouček Z, Graham MWR de V (1978) Chalcidoidea. In: Fitton, MG, Graham MWR de V, Bouček ZRJ, Fergusson NDM, Huddleston T, Quinlan J, Richards OW (Eds) A Check List of British Insects, second edition (completely revised). Handbooks for the Identification of British Insects XI, part 4, 67-110.

Brown RW (1978) Composition of scientific words: a manual of methods and a lexicon of materials for the practice of logotechnics. Smithsonian Institution Press, Washington, DC, $882 \mathrm{pp}$.

Curtis J (1829) A guide to an arrangement of British insects. London, 256 pp.

Curtis J (1832) British entomology; being illustrations and descriptions of the genera of British insects found in Great Britain and Ireland: containing coloured figures from nature of the most rare and beautiful species, and in many instances of the plants upon which they are found. Vol. 9, Richard Taylor, London, plates 386-481, with text.

Dalla Torre CG de (1898) Subfam. Mymarinae. Catalogus hymenopterorum hucusque descriptorum systematicus et synonymicus. Vol. 5: Chalcididae et Proctotrupidae. Guilelmi Engelmann, Lipsiae [Leipzig], 422-431.

Debauche HR (1948) Étude sur les Mymarommidae et les Mymaridae de la Belgique (Hymenoptera Chalcidoidea). Mémoires du Musée Royal d'Histoire Naturelle de Belgique 108: $1-248+24$ plates.

Debauche HR (1949) Mymaridae (Hymenoptera Chalcidoidea). Exploration du Parc National Albert, Mission G.F. de Witte (1933-35) 49: 1-105 + 13 plates.

Gahan AB, Fagan MM (1923) The type species of the genera of Chalcidoidea or chalcid-flies. Bulletin of the United States National Museum 124: 1-173.

Girault AA (1909) A monographic catalogue of the mymarid genus Camptoptera Foerster, with description of one new North American form. Annals of the Entomological Society of America 2: 22-29.

Girault AA (1915) Australian Hymenoptera Chalcidoidea — II. Second supplement. Memoirs of the Queensland Museum 3: 154-169.

Graham MWR de V (1982) The Haliday collection of Mymaridae (Insecta, Hymenoptera, Chalcidoidea) with taxonomic notes on some material in other collections. Proceedings of the Royal Irish Academy, B 82: 189-243.

Haliday AH (1833) Essay on the classification of the parasitic Hymenoptera of Britain, which correspond with the Ichneumones minuti of Linnaeus. Entomologist Magazine 1: 259276, 333-350.

Hellén W (1974) Die Mymariden Finnlands (Hymenoptera: Chalcidoidea). Fauna Fennica 25: $1-31$.

Hincks WD (1959) The British species of the genus Alaptus Haliday in Walker (Hym., Chalc., Mymaridae). Transactions of the Society for British Entomology 13: 137-148. 
Huber JT (1992) The subgenera, species groups, and synonyms of Anaphes (Hymenoptera: Mymaridae) with a review of the described Nearctic species of the fuscipennis group of Anaphes s.s. and the described species of Anaphes (Yungaburra). Proceedings of the Entomological Society of Ontario 123: 23-110.

Huber JT (2006) [2004] Review of the described Nearctic species of the crassicornis group of Anaphes s.s. (Hymenoptera: Mymaridae). Journal of the Entomological Society of Ontario 135: 3-86.

Huber JT, Lin N-Q (1999) World review of the Camptoptera group of genera (Hymenoptera: Mymaridae). Proceedings of the Entomological Society of Ontario 130: 21-65.

ICZN (1965) Mymar Curtis, 1829 (Insecta, Hymenoptera): designation of a type-species under the plenary powers. Opinion 729. Bulletin of Zoological Nomenclature 22(2): 82-83.

Kryger JP (1950) The European Mymaridae comprising the genera known up to c. 1930. Entomologiske Meddelelser 26: 1-97.

Noyes JS (2009) Universal Chalcidoidea database. http://www.nhm.ac.uk/research-curation/ research/projects/chalcidoids/

Rooseboom M (1956) Microscopium. Rijksmuseum voor de Geschiedenis der Natuurwetenschappen (National Museum for the History of Science) No. 95. Leyden, 59 pp.

Schmiedeknecht O (1909) Hymenoptera Fam. Chalcididae. Genera Insectorum 97: 1-558 + 8 plates.

Shaw G (1798) Account, accompanied by a figure, of a minute Ichneumon. Transactions of the Linnaean Society of London 4: 189 and plate 18, fig. 1.

Soyka W (1949) Monographie der Mymar-Gruppe mit den Gattungen Mymar Curtis, Synanaphes Soyka, Ferrierella Soyka, Anaphoidea Girault, Hofenederia Soyka, Fulmekiella Soyka, und Yungaburra Girault (Hymenoptera, Chalcidoidea, Mymaridae). Revista de Entomologia, Rio de Janeiro 20: 301-422.

Soyka W (1955) Neue Revision der Gattung Mymar Curtis (Mymaridae, Chalcidoidea, Hymenoptera). Mitteilungen der Münchner Entomologischen Gesellschaft 44/45: 460-475.

Soyka W (1961) Neue Monographische Revision der Camptoptera - Gruppe mit den Gattungen Camptoptera Förster, Stichothrix Förster, Macrocamptoptera Girault und Wertanekiella n.g.* (Mymaridae, Chalcidoidea, Hymenoptera). Publicaties van het Natuurhistorish Genootschap in Limburg 12: 72-89.

Triapitsyn SV (2010) Revision of the Palaearctic species and review of the Oriental species of Ooctonus (Hymenoptera: Mymaridae), with notes on extralimital taxa. Zootaxa 2381: 1-74.

Westwood JO (1840) Synopsis of the genera of British insects : 1-154 + Addenda to the generic synopsis of British insects: 155-158. [Issued at the end of: An introduction to the modern classification of insects; founded on the natural habits and corresponding organization of the different families. Longman, Orme, Brown, Green, and Longmans, London, 2: i-xi + 1-587.] 